\title{
Protection of taurine and granulocyte colony- stimulating factor against excitotoxicity induced by glutamate in primary cortical neurons
}

\author{
Chunliu Pan ${ }^{1}$, Amit Gupta ${ }^{2}$, Howard Prentice ${ }^{2^{*}}$, Jang-Yen Wu ${ }^{2^{*}}$ \\ From $17^{\text {th }}$ International Meeting of Taurine \\ Fort Lauderdale, FL, USA. 14-19 December 2009
}

\begin{abstract}
s
Background: Both taurine, an inhibitory neurotransmitter and granulocyte colony-stimulating factor (G-CSF), a growth factor, possess neuroprotective and neurotrophic properties in vitro. However, the mechanisms of their underlying neuroprotective effects are not fully understood.

Methods: In the present study, we investigated the potential protective benefits of taurine, G-CSF and the combination of taurine and G-CSF against excitotoxicity induced by glutamate in primary cortical neuronal cultures.

Results: $25 \mathrm{mM}$ taurine, $25 \mathrm{ng} / \mathrm{ml} \mathrm{G-CSF}$ and the combination of $25 \mathrm{mM}$ taurine and $25 \mathrm{ng} / \mathrm{ml}$ G-CSF showed a protective effect reaching $75 \%, 75 \%$ and $88 \%$, respectively. Furthermore, taurine exerted its protective effect through down-regulation of expression of GRP 78, CHOP, Bim and caspase 12.

Conclusion: The results showed that all of these treatments, taurine, G-CSF and the combination of taurine and G-CSF, protected primary cortical neurons against excitotoxicity induced by glutamate. ER stress is suppressed by taurine after glutamate toxicity.
\end{abstract}

\section{Background}

Taurine (2-aminoethanesulfonic acid), an inhibitory neurotransmitter, is present at high concentrations in many invertebrate and vertebrate systems [1-3]. Taurine has received much attention in the field of neuroprotection since the original experiments of Curtis and Watkins on the synaptic effects of inhibitory and excitatory amino acids $[4,5]$. Taurine is at a high level in the immature brain, serving as a trophic factor [6]. It has been thought to induce hyperpolarization, to inhibit firing of central neurons and to act as a modulator of synaptic activity in the brain [7-9]. The maintenance of the integrity of membranes, transmembrane $\mathrm{Cl}^{-}$flux and intracellular calcium homeostasis are also important functions of taurine in the brain [10-13]. Taurine also acts as an osmoregulator and plays an antioxidant role [14-16]. In

\footnotetext{
* Correspondence: hprentic@fau.edu; jwu@fau.edu

${ }^{2}$ College of Biomedical Science, Florida Atlantic University, Boca Raton, FL 33431, USA

Full list of author information is available at the end of the article
}

addition, it has been related to neuroprotection against multiple neurological diseases including Alzheimer'sdisease, Huntington's disease and brain ischemia [17-19]. Moreover, taurine was found in neuronal systems to exert a protective function against toxicity induced by glutamate [20,21].

G-CSF is one of the few growth factors currently approved for clinical use for routine treatment of neutropenia [22]. It primarily stimulates proliferation, differentiation and maturation of cells committed to the neutrophilic granulocyte lineage through binding to the specific G-CSF receptor [23]. G-CSF also has been shown to have trophic effects on neuronal cells in vitro [24]. Moreover, G-CSF is an effective neuroprotectant in the treatment of a number of neurological diseases including stroke, Parkinson's disease and Alzheimer's disease [25-28]. In addition, apart from its protective role in neurons, G-CSF also dampens systemic inflammatory reactions, which may be of additional benefit in neurodegenerative conditions [29]. 
Although it is established that taurine and G-CSF have many beneficial effects under a variety of conditions of cell damage, the protective mechanisms are still unclear. We have recently demonstrated that taurine protects PC12 cells against ER stress induced by oxidative stress [30]. Here, we studied the protective effect of taurine, G-CSF and the combination of taurine and G-CSF against excitotoxicity induced by glutamate in rat primary neuronal cultures. We demonstrated that ER stress is also involved in the excitotoxicity induced by glutamate. Moreover, taurine protects primary neurons by suppressing ER stress induced by glutamate.

\section{Methods}

\section{Materials}

Basal medium-Eagle, fetal bovine serum, poly-D-lysine, taurine, Penicillin-Streptomycin and other chemicals were purchased from Sigma (St. Louis, MO, USA). Mouse anti-actin, rabbit anti-GRP78, rabbit anti-CHOP/ GADD153, rabbit anti-caspase-12 antibodies and secondary mouse and rabbit antibodies were purchased from Santa Cruz Biotechnology (Santa Cruz, CA, USA). Rabbit anti-Bim antibody was purchased from Assay Designs (Ann Arbor, Michigan, USA). Adenosine 5'-triphosphate (ATP) Bioluminescent assay kit was purchased from Promega (Madison, WI, USA). RIPA buffer was purchased from Thermo Scientific (Rockford, IL, USA). Pregnant Sprague Dawley rats were purchased from Harlan (Indianapolis, IN) and housed in the animal care facility at Florida Atlantic University. The procedures for the care and use of rats, in accordance with the National Institutes of Health Guidelines for the Care and Use of Laboratory Animals, were approved by the Institutional Animal Care and Use Committee of Florida Atlantic University.

\section{Primary cortical neuronal cell culture}

Primary cortical neuronal cell cultures were prepared using a previously described protocol [13]. Briefly, rat embryos at 17-18 days were removed and brains were isolated from the fetuses and kept in basal media Eagle (BME) supplemented with $2 \mathrm{mM}$ glutamine, $26.8 \mathrm{mM}$ glucose, and $20 \%$ heat-inactivated fetal bovine serum. This medium is referred to as growth medium-eagle (GME). The cortices then were dissociated by passing the tissue through a 14-G cannula. Cells were centrifuged at $200 \mathrm{~g} / \mathrm{min}$ for $5 \mathrm{~min}$ at $25^{\circ} \mathrm{C}$. The resulting pellet was resuspended in GME and plated on appropriate tissue culture plates precoated with $5 \mathrm{ug} / \mathrm{ml}$ of polyD-lysine. Cells were maintained for 1 hour in a humidified incubator $\left(37^{\circ} \mathrm{C}, 99 \%\right.$ humidity and $\left.5 \% \mathrm{CO} 2\right)$ before the incubation medium was replaced with serum-free neurobasalmedium (GIBCO) supplemented with B27 and $500 \mathrm{uM}$ glutamine. The cultures were maintained in an incubator for $14-18$ days.

\section{Measurement of cell viability}

Cells were measured by ATP assay. Neurons at 14 days in vitro were preincubated with $25 \mathrm{mM}$ taurine for 1 hour. Then the neurons were treated with $100 \mathrm{uM}$ glutamate for 4 hours. ATP solution was added to each well and cells were incubated for 10 minutes, after which levels of ATP were quantified in a luciferase reaction. The luminescent intensity was measured using a luminometer (SpectraMax, Molecular Devices) after transferring the lysate to a standard opaque walled multi-well plate.

\section{Western blot analysis}

Primary cortical neuron cultures were lysed in RIPA buffer (25 mM Tris- $\mathrm{HCl} \mathrm{pH} \mathrm{7.6,} 150 \mathrm{mM} \mathrm{NaCl}, 1 \% \mathrm{NP}-$ $40,1 \%$ sodium deoxycholate, $0.1 \%$ SDS) containing $1 \%$ (v/v) mammalian protease inhibitor cocktail from Sigma and separated on a SDS-PAGE. After proteins were transferred to a nitrocellulose membrane, the membrane was then blocked in blocking buffer $(20 \mathrm{mM}$ Tris- $\mathrm{HCl}$, $150 \mathrm{mM} \mathrm{NaCl}, 0.1 \%$ Tween-20, 5\% milk) for 1.5 hours at room temperature. After blocking, the corresponding primary antibody was incubated for one hour, followed by one hour incubation with the corresponding HRPconjugated secondary antibody at room temperature. Extensive washes with blocking buffer were performed between each step. The protein immuno-complex was visualized using ECL detection reagents.

\section{Statistical analysis}

All data shown were expressed as the mean \pm SEM. The Student's t-test or one-way ANOVA was used to compare means between groups. Differences of $\mathrm{P}<0.05$ were considered statistically significant.

\section{Results}

Dose-dependent glutamate toxicity in primary neuron cultures

Excessive levels of the neurotransmitter glutamate trigger excitotoxic processes in neurons that result in cell death [31].To identify the excitotoxic dose range of glutamate, rat cortical neurons were treated for 4 hours with $50,100,200$ or $300 \mathrm{uM}$ glutamate respectively. The results are shown in Fig. 1. We found that glutamate treatment caused a dose-dependent increase in neuronal apoptotic processes. There was approximately $50 \%$ survival of cortical neurons with $100 \mathrm{uM}$ glutamate treatment for 4 hours (Fig. 1, lane 3). 100 uM glutamate was chosen as an optimal concentration to induce the excitotoxicity. 


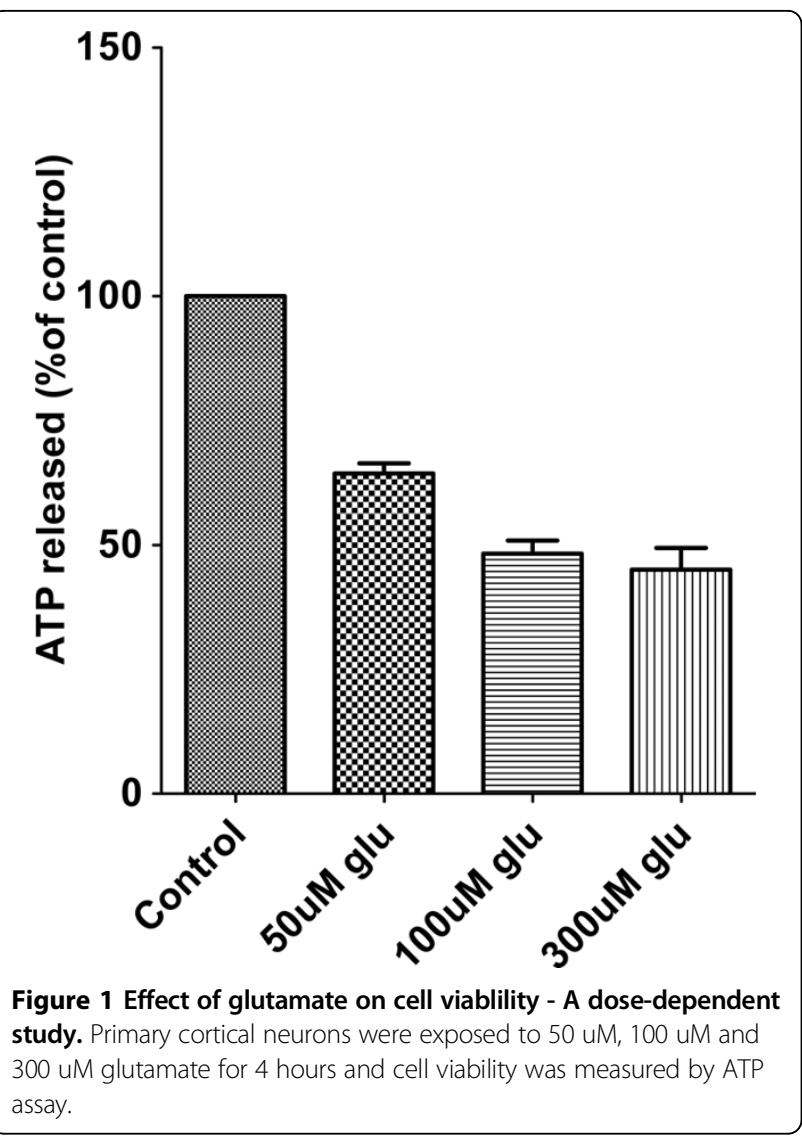

Protective effects of taurine against glutamate toxicity in primary neuron cultures

Previously, we found that $25 \mathrm{mM}$ taurine resulted in the optimal neuroprotection against glutamate induced excitotoxicity [32]. For this reason, we selected the $25 \mathrm{mM}$ taurine concentration for testing cell viability using the ATP assay. For testing the protective effect of $25 \mathrm{mM}$ taurine against glutamate in cortical neurons, cells were seeded in 96-well plates and treated with or without $25 \mathrm{mM}$ taurine for 1 hour followed by $100 \mathrm{uM}$ glutamate exposure for 4 hours. The cell survival results are shown in Fig. 2. The treatment of $25 \mathrm{mM}$ taurine increased the cell survival by $75 \%$ compared to the condition with $100 \mathrm{uM}$ glutamate treatment.

Protection of G-CSF against glutamate toxicity in primary neuronal cultures

G-CSF has been widely investigated in terms of protection of neurons in stroke, as shown in numerous papers [25,26,33-36]. Glutamate has been shown to play a key role in the pathogenesis of stroke [37]. However, there has been little research on the protective function of GCSF in glutamate induced excitotoxicity in vitro. G-CSF was previously shown to exhibit a protective effect in cerebellar granule cells exposed to glutamate toxicity

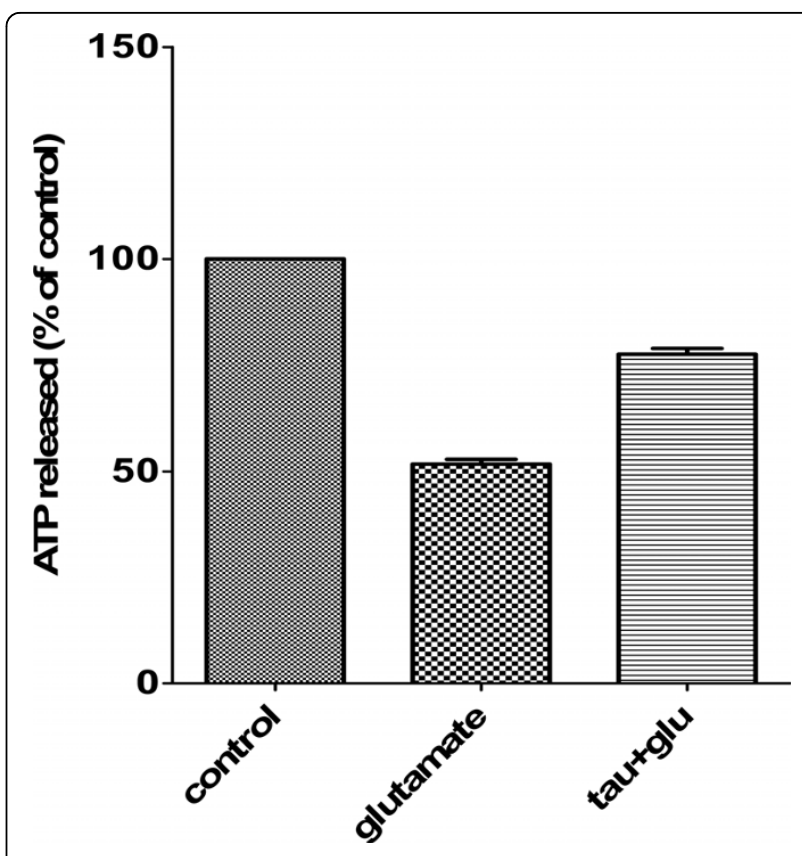

Figure 2 Neuroprotective effect of taurine against glutamateinduced excitotoxicity measured by ATP assay. Primary cortical neurons were treated with $25 \mathrm{mM}$ taurine for 1 hour before exposure to 100uM glutamate for 4 hours and cell viability was measured by ATP assay.

[25]. In the current study, we demonstrated the protective function of G-CSF at a range of concentrations from 10 to $40 \mathrm{ng} / \mathrm{ml}$ against excitotoxicity induced by glutamate in primary neuronal cultures (Fig. 3). G-CSF treatment resulted in an enhanced cell survival at several concentrations, with the highest protection of $75 \%$ occurring at $25 \mathrm{ng} / \mathrm{ml}$.

\section{The protective effect of the combination of taurine and} G-CSF in primary neuronal cultures

To test whether the combination of taurine and G-CSF promotes protection against glutamate induced toxicity, we treated primary neurons with $25 \mathrm{mM}$ taurine plus 25 $\mathrm{ng} / \mathrm{ml}$ G-CSF for 1 hour, followed by glutamate treatment for 4 hours. The results are shown in Fig. 4 . The combination of taurine and G-CSF increased the protective effect against glutamate toxicity to $88 \%$ cell survival compared to $75 \%$ cell survival from taurine or G-CSF treatment alone.

Taurine protects neurons against glutamate excitotoxicity by suppressing the expression of GRP78, CHOP,

\section{Caspase-12 and Bim}

To investigate if ER stress can be induced by glutamate and then suppressed by taurine, specific ER stress effector proteins were analyzed by western blot. Glucose regulated protein-78 (GRP78) is an ER-associated 


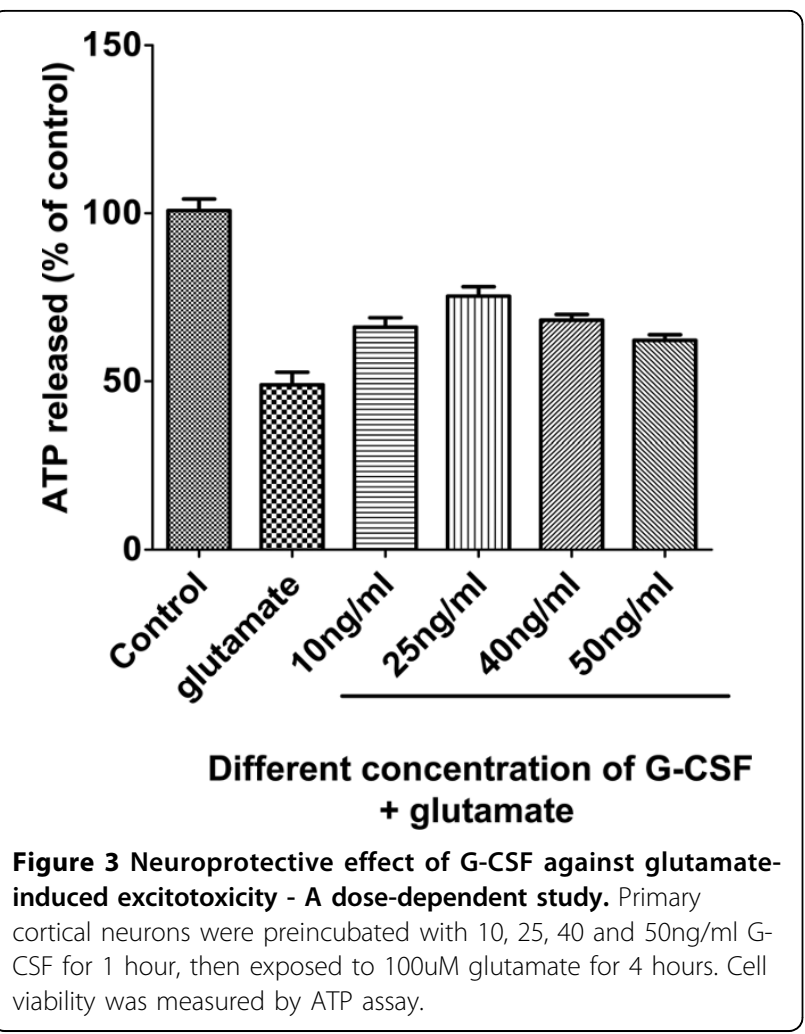

chaperone, which facilitates protein folding in ER [38]. The expression of GRP78 protein was up-regulated in primary neurons after treatment with $100 \mathrm{uM}$ glutamate for 4 hours. However, taurine restored the level of GRP78 to control levels, as shown in Fig. 5. C/EBP homologous protein (CHOP), also known as growth arrest and DNA damage inducible protein 153 (GADD153), is an important ER stress marker [39]. Fig. 6 shows that the expression of CHOP was up-regulated by glutamate. Taurine treatment restored CHOP expression to the control level (Fig. 6). Both Caspase-12 and Bim play an essential role in the progression of programmed cell death during the proapoptotic phase of the ER stress response $[40,41]$. Taurine reversed the induction of Caspase-12 and Bim caused by glutamate in primary neurons, as shown in Fig. 5 and Fig. 6.

\section{Discussion}

In the present study, we have demonstrated the potent protection by taurine and by G-CSF in an in vitro model of primary cortical neuronal cell death induced by glutamate. Taurine and G-CSF protected primary cortical neurons against glutamate-induced neurotoxicity as determined by measuring cell viability using the ATP assay. On the other hand, we found that the combination of taurine and G-CSF gave a synergistic enhancement of protection against glutamate in primary cortical neurons. We have further shown that the suppression of

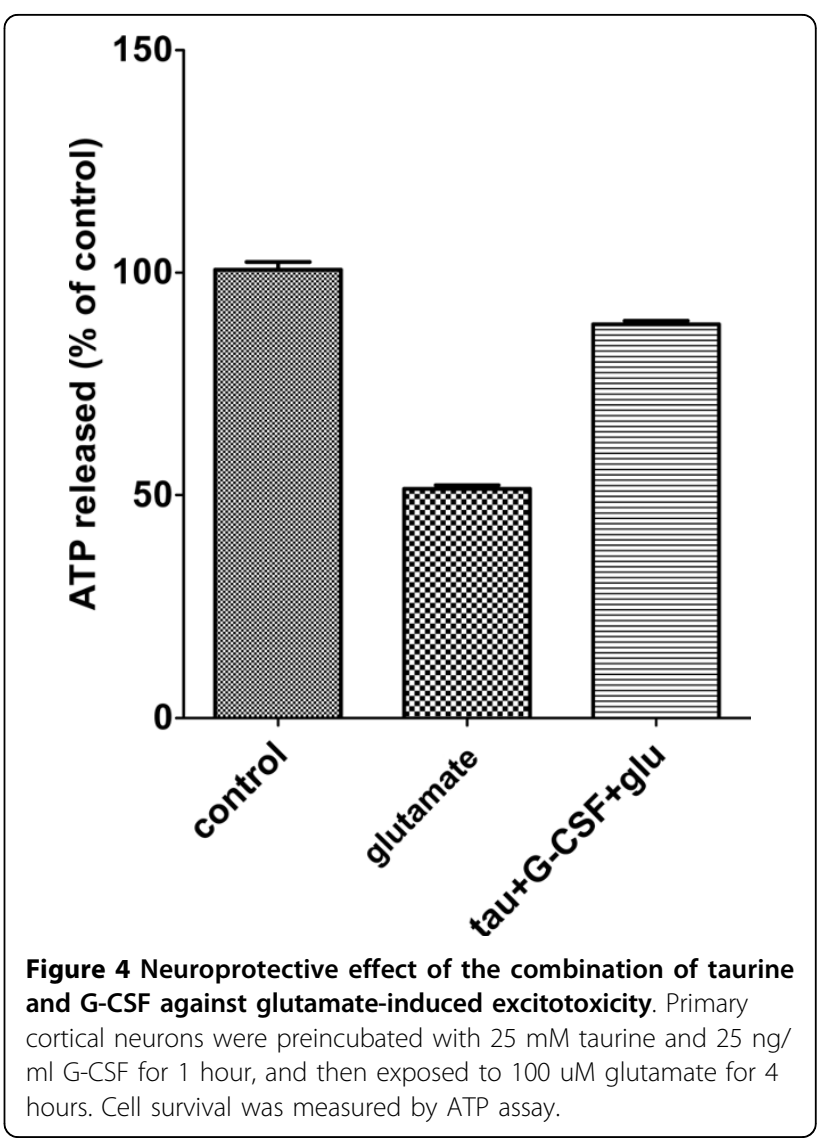

ER stress is an essential underlying mechanism for taurine-induced neuroprotection. Our investigation of the intracellular mechanisms downstream of ER stress demonstrated a reversal by taurine of glutamate-induced increases in GRP78, CHOP, Caspase-12 and Bim levels.

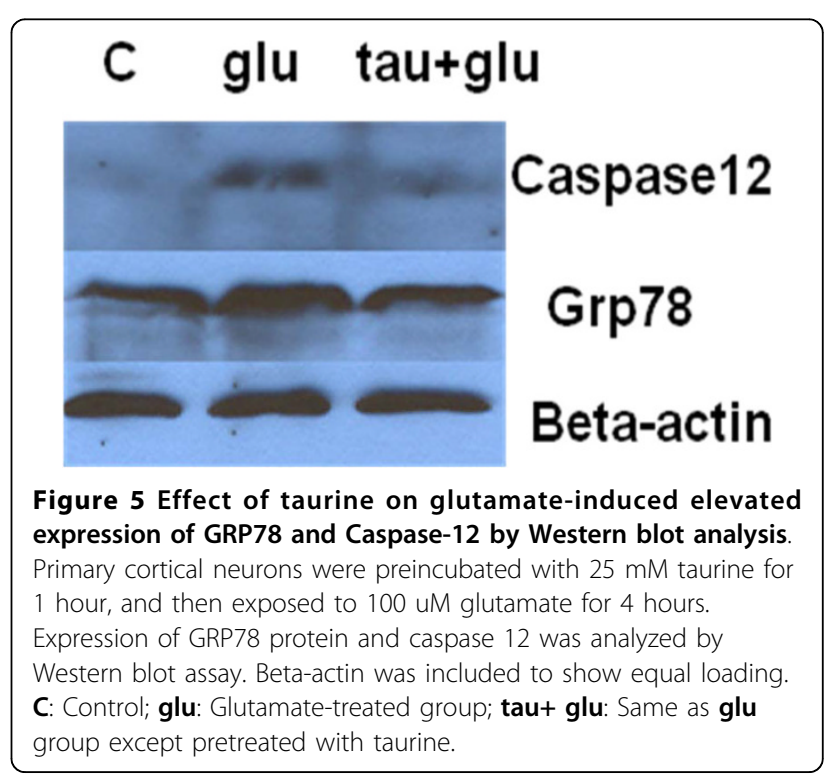




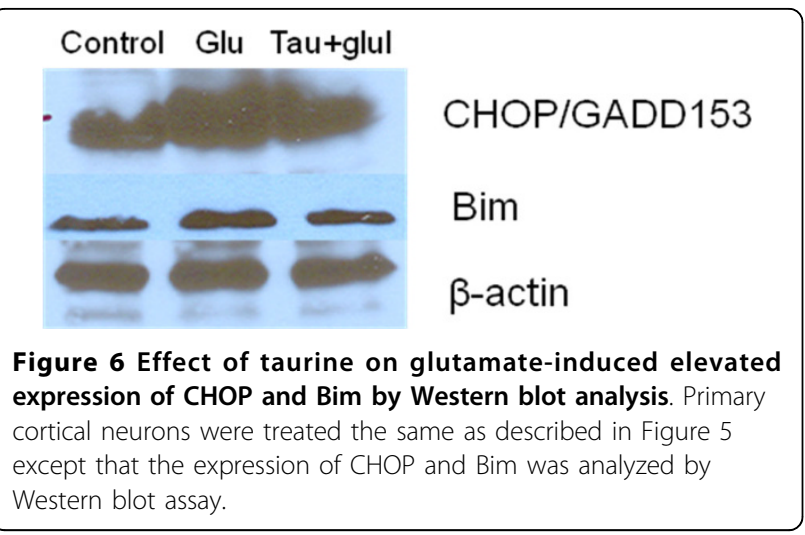

A previous paper reported that taurine and basic fibroblast growth factor (bFGF) in combination gave an enhanced neuroprotection in granule neurons against glutamate induced excitotoxicity [42]. They showed that neuroprotection was obtained only through the combined action of taurine and bFGF in a cerebellar granule neuron rich culture, but not by these factors alone. Therefore, they believed that taurine can augment bFGF function under certain conditions. Here, we demonstrated that taurine or G-CSF administrated alone showed a neuroprotective effect. Furthermore, an enhanced protection against glutamate was also observed with a combination of taurine and G-CSF. The clinical application of taurine was investigated and found to be effective in studies as early as 1974 when it was applied to treatment for refractory epilepsy [43]. Both taurine and G-CSF have been shown to be potential drugs for ischemia or stroke in clinical applications $[44,45]$. Since the combination of taurine and G-CSF have synergistic neuroprotective effects against glutamate excitotoxicity, as demonstrated in this paper, this strongly suggests that the combination of taurine and G-CSF may be more effective than the individual agents in treatment of neurological diseases, such as stroke.

Many neurological disorders such as Alzheimer's disease, stroke and Parkinson's disease have been linked to the overactivation of glutamatergic transmission and excitotoxicity as a common pathway of neuronal injury [46-48]. Previous studies have also shown that ER stress is induced in neurons by glutamate toxicity $[49,50]$. Recently, kainic acid (KA), a non-NMDA glutamate receptor agonist, was found to cause the disintegration of the ER membrane in hippocampal neurons and to cause ER stress [51]. In this study, we demonstrated glutamate induced ER stress associated with the up-regulation of the proteins GRP78, CHOP, Bim and caspase- 12 .

Although taurine has been investigated and applied to treat many diseases, the protective mechanism is still not fully understood. We have already demonstrated that ER stress induced by $\mathrm{H}_{2} \mathrm{O}_{2}$ in $\mathrm{PC} 12$ cells was prevented by taurine treatment [30]. In the present study, our results show that taurine reduces the ER stress induced by glutamate in primary neuronal cultures.

\section{Conclusion}

In the present study, we demonstrated that both taurine and G-CSF protect primary cortical neurons against glutamate-induced cell death. Interestingly, we found that the combination of taurine and G-CSF results in an enhanced protective effect. Because both taurine and GCSF are neuroprotective agents that are approved for clinical use, the combined administration of these two factors may constitute a viable therapy with potentially enhanced therapeutic efficacy. Moreover, taurine suppressed the ER stress induced by glutamate. Further investigation will be performed to examine the specific pathway responsible for ER stress induced by glutamate and to identify molecular targets in the ER stress pathway that are specifically inhibited by taurine, G-CSF and their combination.

\section{Acknowledgements}

This work was supported in part by the James and Esther King Biomedical Research Program, Florida Department of Health.

This article has been published as part as part of Journal of Biomedical Science Volume 17 Supplement 1, 2010: Proceedings of the 17th International Meeting of Taurine. The full contents of the supplement are available online at http://www.jbiomedsci.com/supplements/17/S1.

\section{Author details}

'Department of Chemistry and Biochemistry, Florida Atlantic University, Boca Raton, FL 33431, USA. ${ }^{2}$ College of Biomedical Science, Florida Atlantic University, Boca Raton, FL 33431, USA.

\section{Competing interests}

The authors declare that they have no competing interests.

Published: 24 August 2010

\section{References}

1. Huxtable RJ: The physiological actions of taurine. Physiol. Rev 1992, 72:101-163.

2. Sturman JA: Taurine in development. Physiol. Rev 1993, 73:119-147.

3. Huxtable RJ: Taurine in the central nervous system and the mammalian actions of taurine. Prog. Neurobiol 1989, 32:471-533.

4. Curtis DR, Watkins JC: The excitation and depression of spinal neurones by structurally related amino acids. J. Neurochem 1960, 6:117-141.

5. Curtis DR, Watkins JC: Analogues of glutamic and gamma-aminobutyric acids having potent action on mammalian neurons. Nature (Lond) 1961, 191:1010.

6. Palackal T, Kujawa M, Moretz RC, Neuringer M, Sturman JA: Laminar analysis of the number of neurons, astrocytes, oligodendrocytes amd microglia in the visual cortex (area 17) of 3-month-old rhesus monkeys fed a human infant soy-protein formula with or without taurine supplementation from birth. Dev. Neurosci 1991, 13:20-33.

7. Kuriyama K: Taurine as a neuromodulator. Fed. Proc 1980, 39:2680-2684.

8. Oja SS, Saransaari P: Taurine as osmoregulator and neuromodulator in the brain. Metab Brain Dis 1996, 11:153-164.

9. Saransaari P, Oja SS: Release of GABA and taurine from brain slices. Prog. Neurobiol 1992, 38:455-482. 
10. Moran J, Salazar P, Pasantes-Morales H: Effect of tocopherol and taurine on membrane fluidity of retinal rod outer segments. Exp Eye Res 1987, 45:769-776.

11. Okamoto K, Kimura H, Sakai Y: Taurine-induced increase of the $\mathrm{Cl}$ conductance of cerebellar Purkinje cell dendrites in vitro. Brain Res 1983, 259:319-323.

12. Satoh $\mathrm{H}$, Sperelakis $\mathrm{N}$ : Review of some actions of taurine on ion channels of cardiac muscle cells and others. Gen. Pharmacol 1998, 30:451-463.

13. Chen WQ, Jin $\mathrm{H}$, Nguyen M, Carr J, Lee YJ, Hsu CC, Faiman MD, Schloss JV, Wu JY: Role of taurine in regulation of intracellular calcium level and neuroprotective function in cultured neurons. J Neurosci Res 2001, 66:612-619.

14. Wade JV, Olson JP, Samson FE, Nelson SR, Pazdernik TL: A possible role for taurine in osmoregulation within the brain. J. Neurochem 1988, 51:740-745.

15. Militante J, Lombardini JB: Age-related retinal degeneration in animal models of aging: Possible involvement of taurine deficiency and oxidative stress. Neurochem Res 2004, 29:151-160.

16. Balkan J, Kanbagli O, Hatipoglu A, Kucuk M, Cevikbas U, Toker G, Uysal M: Improving effect of dietary taurine supplementation on the oxidative stress and lipid levels in the plasma, liver and aorta of rabbits fed on a high-cholesterol diet. Biosci Biotechnol Biochem 2002, 66:1755-1758.

17. Takatani T, Takahashi K, Uozumi Y, Shikata E, Yamamoto Y, Ito T, Matsuda T, Schaffer SW, Fujio Y, Azuma J: Taurine inhibits apoptosis by preventing formation of the Apaf-1-caspase-9 apoptosome. Am J Physiol Cell Physiol 2004, 287:C949-C953.

18. Paula-Lima AC, Felice GF, Brito-Moreira J, Ferreira TS: Activation of GABAA receptors by taurine and muscimol blocks the neurotoxicity of betaamyloid in rat hippocampal and cortical neurons. Neuropharmacology 2005, 49:1140-1148.

19. Tadros GM, Khalifa EA, Abdel-Naim BA, Arafa Huntingtons: Neuroprotective effect of taurine in 3-nitropropionic acid-induced experimental animal model of Huntington's disease phenotype. Pharmacol Biochem Behav 2005, 82:574-582.

20. Ward R, Cirkovic-Vellichovia T, Ledeque F, Tirizitis G, Dubars G, Datla K, Dexter D, Heushling $P$, Crichton R: Neuroprotection by taurine and taurine analogues. Adv Exp Med Biol 2006, 583:299-306.

21. Wu JY, Wu H, Jin Y, Wei J, Sha D, Prentice $H$, Lee HH, Lin $C H$, Lee $Y H$, Yang LL: Mechanism of Neuroprotective Function of Taurine. Adv Exp Med Biol 2009, 643:169-179.

22. Metcalf D: The colony stimulating factors discovery, development, and clinical applications. Cancer 1990, 65:2185-95.

23. Hartung T: Anti-inflammatory effects of granulocyte colony-stimulating factor. Curr Opin Hematol 1998, 5:221-225.

24. Konishi Y, Chui DH, Hirose H, Kunishita T, Tabira T: Trophic effects of erythropoeitin and other hematopoietic factors on central cholinergic neurons in vitro and in vivo. Brain Res 1993, 609:29-35.

25. Schabitz WR, Kollmar R, Schwaninger M, Juettler E, Bardutzky J, Scholzke MN, Sommer C, Schwab S: Neuroprotective effect of granulocyte colonystimulating factor after focal cerebral ischemia. Stroke 2003, 34:745-751.

26. Solaroglu I, Tsubokawa T, Cahill J, Zhang JH: Anti-apoptotic effect of granulocyte-colony stimulating factor after focal cerebral ischemia in the rat. Neuroscience 2006, 143:965-974.

27. Meuer $K$, Pitzer $C$, Teismann $P$, Krüger $C$, Göricke $B$, Laage $R$, Lingor $P$, Peters K, Schlachetzki JC, Kobayashi K, Dietz GP, Weber D, Ferger B, Schäbitz WR, Bach A, Schulz JB, Bähr M, Schneider A, Weishaupt JH: Granulocyte-colony stimulating factor is neuroprotective in a model of Parkinson's disease. J Neurochem 2006, 97:675-686.

28. Tsai KJ, Tsai YC, Shen CK: G-CSF rescues the memory impairment of animal models of Alzheimer's disease. J Exp Med 2007, 204:1273-1280.

29. Hartung T: Anti-inflammatory effects of granulocyte colony-stimulating factor. Curr Opin Hematol 1998, 5:221-225.

30. Pan C, Giraldo GS, Prentice H, Wu JY: Taurine protection of PC12 cells against endoplasmic reticulum stress induced by oxidative stress. $J$ Biomed Sci 2010, 17(Suppl 1):S17.

31. Meldrum B, Garthwaite J: Excitatory amino acid neurotoxicity and neurodegenerative disease. Trends Pharmacol Sci 1990, 11:379-87.

32. Leon $R$, Wu $H$, Jin $Y$, Wei J, Buddhala $C$, Prentice $H$, Wu J-Y: Protective function of taurine in glutamate-induced apoptosis in cultured neurons. J Neurosci Res 2009, 87:1185-1194.
33. Hasselblatt M, Jeibmann A, Riesmeier B, Maintz D, Schaitz W-R: Granulocyte-colony stimulating factor (G-CSF) and G-CSF receptor expression in human ischemic stroke. Acta Neuropathol 2007, 113:45-51.

34. Lee S-T, Chu K, Jung K-H, Ko S-Y, Kim E-H, Sinn D-I, Lee Y-S, Lo EH, Kim M, Roh J-K: Granulocyte colony-stimulating factor enhances angiogenesis after focal cerebral ischemia. Brain Res 2005, 1058:120-128.

35. Yataa K, Matchettc AG, Tsubokawaa T, Tanga J, Kanamarud K, Zhang HJ: Granulocyte-colony stimulating factor inhibits apoptotic neuron loss after neonatal hypoxia-ischemia in rats. Brain Res 2007, 1145:227-238.

36. Chen WF, Jean YH, Sung CS, Wu GJ, Huang SY, Ho JT, Su TM, Wen ZH: Intrathecally injected ranulocyte colony-stimulating factor produced europrotective effects in spinal cord ischemia via the mitogen-activated protein kinase and Akt pathways. Neuroscience 2008, 153:31-43.

37. Aliprandi A, Longoni M, Stanzani L, Tremolizzo L, Vaccaro M, Begni B, Galimberti G, Rosanna G, Ferrarese C: Increased plasma glutamate in stroke patients might be linked to altered platelet release and uptake. J Cereb Blood Flow Metab 2005, 25:513-519.

38. Kaufman RJ: Orchestrating the unfolded protein response in health and disease. J Clin Invest 2002, 110:1389-1398.

39. Ferri KF, Kroemer G: Organelle-specific initiation of cell death pathways. Nat Cell Biol 2001, 3:E255-E263.

40. Puthalakath $H$, O'Reilly LA, Gunn P, Lee L, Kelly PN, Huntington ND, Hughes PD, Michalak EM, McKimm-Breschkin J, Motoyama N, Gotoh T, Akira $S$, Bouillet $P$, Strasser $A$ : ER stress triggers apoptosis by activating BH3-only protein Bim. Cell 2007, 129(z):1337-1349.

41. Nakagawa T, Zhu H, Morishima N, Li E, Xu J, Yankner BA, Yuan J: Caspase 12 mediates endoplasmic-reticulum-specific apoptosis and cytotoxicity by amyloid-beta. Nature 2000, 403:98-103.

42. Idrissi EA, Trenkner E: Growth factors and taurine protect against excitotoxicity by stabilizing calcium homeostasis and energy metabolism. J Neurosci 1999, 19:9459-9468.

43. Bergamini L, Mutani R, Delsedime M, Durelli L: First clinical experience on the antiepileptic action of taurine. Eur Neurol 1974, 11:261-269.

44. McCarty MF: The reported clinical utility of taurine in ischemic disorders may reflect a down-regulation of neutrophil activation and adhesion Med Hypotheses 1999, 53:290-299.

45. Schäbitz WR: Developing granulocyte-colony stimulating factor for the treatment of stroke: Current status of clinical trials. Stroke 2006, 37:1654.

46. Aliprandi1 A, Longoni M, Stanzani L, Tremolizzo L, Vaccaro M, Begni B, Galimberti G, Garofolo R, Ferrarese C: Increased plasma glutamate in stroke patients might be linked to altered platelet release and uptake. J Cereb Blood Flow Metab 2005, 25:513-519.

47. Maragos WF, Greenamyre JT, Penney JB Jr, Young AB: Glutamate dysfunction in Alzheimer's disease: an hypothesis. Trends Neurosci 1987, 10:65-68.

48. Greenamyre JT: Glutamate-dopamine interactions in the basal ganglia relationship to Parkinson's disease. J Neural Transm Gen Sect 1993, 91:255-269.

49. Yu Z, Luo H, Fu W, Mattson MP: The endoplasmic reticulum stressresponsive protein GRP78 protects neurons against excitotoxicity and apoptosis: suppression of oxidative stress and stabilization of calcium homeostasis. Exp. Neurol 1999, 155:302-314.

50. Kitao Y, Ozawa K, Miyazaki M, Tamatani M, Kobayashi T, Yanagi H, Okabe M, Ikawa M, Yamashima T, Stern DM, Hori O, Ogawa S: Expression of the endoplasmic reticulum molecular chaperone (ORP150) rescues hippocampal neurons from glutamate toxicity. J. Clin. Invest 2001 108(z):1439-1450.

51. Sokka AL, Putkonen N, Mudo G, Pryazhnikov E, Reijonen S, Khiroug L, Belluardo N, Lindholm D, Korhonen L: Endoplasmic reticulum stress inhibition protects against excitotoxic neuronal injury in the rat brain. $J$ Neurosci 2007, 27:901-908.

doi:10.1186/1423-0127-17-S1-S18

Cite this article as: Pan et al:: Protection of taurine and granulocyte colony-stimulating factor against excitotoxicity induced by glutamate in primary cortical neurons. Journal of Biomedical Science 2010 17(Suppl 1): S18. 